\title{
Production of High Purity Biosurfactants Using Heavy Oil Residues as Carbon Source
}

\author{
Athina Mandalenaki ${ }^{1}$, Nicolas Kalogerakis ${ }^{1,2}$ (D) and Eleftheria Antoniou ${ }^{1, *(D)}$ \\ 1 School of Environmental Engineering, Technical University of Crete, 73100 Chania, Crete, Greece; \\ amandalenaki@gmail.com (A.M.); nicolas.kalogerakis@enveng.tuc.gr (N.K.) \\ 2 Institute of Petroleum Research, Foundation for Research and Technology Hellas, 73100 Chania, Crete, Greece \\ * Correspondence: eantoniou@isc.tuc.gr
}

check for updates

Citation: Mandalenaki, A.; Kalogerakis, N.; Antoniou, E. Production of High Purity Biosurfactants Using Heavy Oil Residues as Carbon Source. Energies 2021, 14, 3557. https://doi.org/ $10.3390 /$ en14123557

Academic Editor: Ricardo J. Bessa

Received: 21 May 2021

Accepted: 9 June 2021

Published: 15 June 2021

Publisher's Note: MDPI stays neutral with regard to jurisdictional claims in published maps and institutional affiliations.

Copyright: (c) 2021 by the authors. Licensee MDPI, Basel, Switzerland. This article is an open access article distributed under the terms and conditions of the Creative Commons Attribution (CC BY) license (https:// creativecommons.org/licenses/by/ $4.0 /)$.

\begin{abstract}
Typically, oil pollution cleanup procedures following first response actions include dispersion. Crude oil is biodegradable, and its bioavailability can be increased when dispersed into very fine droplets by means of chemical surfactants. Although their use is widely spread in many applications, the latter may prove toxic, depending on the extent of use. The use of biological means, such as bioremediation and biosurfactants, has emerged over the past years as a very promising 'green' alternative technology. Biosurfactants (BSs) are amphiphilic molecules produced by microorganisms during biodegradation, thus increasing the bioavailability of the organic pollutants. It is their biodegradability and low toxicity that render BSs as a very promising alternative to the synthetic ones. Alcanivorax borkumensis SK2 strain ability to produce BSs, without any impurities from the substrate, was investigated. The biosurfactant production was scaled up by means of a sequencing batch reactor (SBR) and a heavy oil residue substrate as the carbon source. The product is free from substrate impurities, and its efficiency is tested on oil bioremediation in the marine environment. The product's dispersion efficiency was determined by the baffled flask test. The production method proposed can have a significant impact to the market, given the ever-increasing demand for ecologically friendly, reliable, commercially viable and economically competitive environmental cleanup techniques.
\end{abstract}

Keywords: rhamnolipids; biosurfactants; bioremediation; sequencing batch reactor; crude oil; hydrocarbons; Alcanivorax borkumensis SK2; heavy oil residues; substrate

\section{Introduction}

Lately, our perception on sustainable development has changed. In the past, sustainable development was defined as developing the quality of life as we live surrounded by our supporting ecosystems. Now the concept of 'sustainability' is emerging to include concomitantly environmental, economic and social equity, enforcing changes to the traditional way consumers and businesses operate and relate to each other. Society has to keep the environment clean by all means while being responsible in consuming and conserving it. The more society recognizes the value of the clean environment, the demand for effective cleanup techniques increases [1,2]. An uncontaminated environment that includes clean air, water, land and energy, is important for human survival, conducting business and making wealth. To this end, scientists, alongside companies and societal needs, make great efforts to improve water quality [2], important for preserving resources and public health. Attention is being paid to environmental sustainability through the development of new green technologies and products, i.e., rainwater management and permeable pavements [3], that aim mainly to reduce pollution from contaminants (for example, BTEX compounds released into a water body that have toxic effects on biota [4] from anthropogenic activities such as fuels, oils and fats, etc. [3]). The replacement of chemical surfactants from the biologically produced ones is a literal case of the situation.

Surfactants (synthetic surfactants and biosurfactants) are amphiphilic molecules with hydrophilic and hydrophobic moieties that participate at surface- or interface-related prop- 
erties [5,6], reducing surface and interfacial tension [7-9]. The repulsive forces between two dissimilar phases are reduced via surfactant addition, and the two phases can mix and interact more easily [10]. Currently produced surfactants are mainly chemically derived from petroleum and are usually toxic and difficult to break down through biodegradation $[5,7,10]$. Their use in the environment results often in an extra source of contamination [11]. Due to their toxic potential, these agents have been increasingly restricted [12]. On the contrary, biosurfactants (BSs) are biodegradable amphiphilic microbial molecules with low toxicity; ability to function in extreme conditions of $\mathrm{pH}$, temperature and salinity with greater selectivity; lower critical micelle concentration (CMC) $[5,7,10]$; resistance to extreme conditions of acidity and basicity; ionic strength and anti-inflammatory and antimicrobial potential [13] and can be produced using as substrates, renewable sources, industrial by-products and wastes $[5,7,10]$. BSs are produced as secondary metabolites $[8,14]$ by a variety of microorganisms such as bacteria (most exploited microorganism), yeast and fungi $[5-7,15]$. They are also produced by plants and animals at slower production rates [14]. BSs are categorized based on their chemical structures in glycolipids, lipoproteins, phospholipids and polymers [6]. The BS activity depends on the BS concentration in the medium. Above the CMC, the BS molecules form micelles, bilayers and vesicles to reduce surface and interfacial tension. Effective BSs can reduce the water-air surface tension from 72 to $30 \mathrm{mN} / \mathrm{m}[6,10]$. Their application range is wide and present in removal of heavy metals, nanotechnology $[5,15]$, petroleum recovery, bioremediation, food industry, detergents, textiles, cosmetics, agricultural industry and pharmaceutics $[5,15,16]$. Their presence in pharmacological activities vary due to their antibacterial, antifungal, antiviral [14,17], anti-mycoplasma [17], anticancer and antiadhesive [14] properties and their biocontrol of plant pathogens [17]. Their most desirable characteristics are their roles in emulsification, foam formation, detergency dispersion $[5,15]$ and wetting. When used in bioremediation the main advantages are the efficiency, safety, and the lack of risk to contaminate the environment [18]. Different groups of biosurfactants have diverse roles in the process in which they are produced, such as the surface area and bioavailability increase of hydrophobic substrates, heavy metal binding, bacteria pathogenesis and biofilm formation [13].

The main obstacles in the large-scale production and commercialization of BSs are the complicated recovery process [5], the high costs of raw materials, the slow growth rates of microorganisms on the substrate, the generally low yields and the final product purification from substrate impurities $[15,19]$. Purification accounts for $60 \%$ of the overall production cost [20]. Efficient BS isolation and purification methods could render their production more economically feasible [10]. Parameters that play a key role in BS-producing cultivations are the isolation of a BS-producing microorganism (strain or consortia) [19], which should be nonpathogenic [12]; the establishment of the best incubation conditions (temperature, time, nutrients, mixing); and the carbon substrate [6]. Choosing appropriate carbon and nitrogen sources is of highest importance for efficient BS production [7]; indeed, the type, quality and quantity of the BS production are affected and influenced by the nature of the carbon substrate [21]. Many by-products or wastes have been used as carbon substrates for the BS production. Some of them are agro-industrial wastes, such as olive oil mill waste, and industrial wastes from animal and plant origin, such as dairy whey and animal fat [15]. Optimized growth/production conditions could lead to more cost-effective and economically viable BS production using cheaper renewable substrates and novel, efficient multistep downstream processing methods [22].

Previously, marine hydrocarbon-degrading consortia and strains from Elefsina Bay, Attica, Greece, were investigated for their BS production efficiency and quality [19]. During this investigation, the isolated bacterial strains were identified and tested for their BS production under several cultivation conditions with different kinds of carbon sources as substrates. Alcanivoracaceae was the most abundant bacteria family, while A. borkumensis SK2 was the dominant strain. This strain is one of the major players in hydrocarbon degradation and is known for its glycolipid production. It is commonly found in contaminated 
areas [19] and is well-known as a standard bioemulsifier [17]. A quite interesting result from this investigation was the fact that the $A$. borkumensis SK2 strain cultivation, with heavy crude oil fractions low in sulfur (HOF-1) as carbon source, produced $70 \mathrm{mg} / \mathrm{L}$ BS. The HOF-1 remained insoluble on the surface of the culture's broth, and the extracted BS did not include any hydrocarbon impurities. With heavy crude oil fractions (HOF) as the carbon source, column chromatography was not necessary to purify the BS for CO impurities [19].

HOF are high in asphaltene concentrations by-products of the oil refining industry. The low cost of this carbon source and the absence of impurities in the BS produced were the incentives to investigate this system further. In this manuscript, our main objectives were to test the BS production of $A$. borkumensis SK2 in a bioreactor, with HOF as the carbon source. In addition, the main questions to be addressed were (a) whether the carbon source would remain insoluble and if so, for how long? (b) What kind of bioreactor should be used? (c) Would the BS produced be without oil impurities and effective in bioremediation?

\section{Materials and Methods}

ONR7a medium (DSMZ 950. ONR7a medium https:/ / www.dsmz.de/microorganisms / medium/pdf/DSMZ_Medium950.pdf (accessed on 18 February 2019)) was used as cultivation medium for Alkanivorax borkumensis SK2. The medium was sterilized in an autoclave before use. Nutrients of nitrogen and phosphorus were used and added in the form of a NP medium in the cultivations. To produce the NP medium, in $1 \mathrm{~L}$ distilled water $\left(\mathrm{dH}_{2} \mathrm{O}\right), 72.48 \mathrm{~g}$ nitrogen as $\mathrm{KNO}_{3}$ and $5.64 \mathrm{~g}$ phosphate as $\mathrm{KH} 2 \mathrm{PO} 4$ (Sigma-Aldrich) were added, and the medium was sterilized in an autoclave. In each $1 \mathrm{~L}$ ONR7a used, $50 \mathrm{~mL}$ NP were added, as to have $0.05 \% w / v$ and $0.005 \% w / v$ nitrogen and phosphorus, respectively. The carbon sources used as substrates in the cultivations were two kinds of heavy oil fractions, HOF-1 and HOF-2, which were sterilized in an autoclave. Those fractions are rich in asphaltenes, with very low solubility, and their concentrations in the cultivations were $0.5 \% w / v$. To handle and add those substrates, they were previously warmed up. HOF-1 (sample name SRAR U-2000, Sarir, sampling Date 26 April 2010) is a petroleum residue low in sulfur from Hellenic Petroleum S.A. in Aspropirgos, and HOF-2 (sample name U31, S-007, sampling Date 27 January 2014) is a vacuum residue from Hellenic Petroleum S.A. in Elefsina Bay.

In a previous reported investigation, Alkanivorax borkumensis SK2 strain was isolated from a bacterial consortium from Elefsina Bay. This strain is known for its glycolipid production and oil degradation ability and was used in all cultivations to produce biosurfactants [19].

For the scaled-up BS production, a bioreactor CH 8636 Wald Switzerland of Bioengineering AG was used. The bioreactor was sterilized in an autoclave before use.

\subsection{Cultivation of Biosurfactant-Producing Bacteria}

The previously isolated biosurfactant-producing strain Alcanivorax borkumensis SK2, a marine bacterial isolate, was used for the biosurfactant production [19]. The pure strain A. borkumensis SK2 was inoculated in $200 \mathrm{~mL}$ of ONR7a artificial seawater supplemented with a HOF-2 used as carbon source $0.5 \% w / v$ and with addition of $10 \mathrm{~mL}$ solution NP. The final ratio of C:N:P was equal to 100:10:1. The cultivation was incubated at $20^{\circ} \mathrm{C}$ on an orbital shaker at $120 \mathrm{rpm}$ for 11 days. For the culture's maintenance, plates supplemented with Zobell Marine broth 2216 HIMEDIA (40.25 g/L) and Agar by Sigma-Aldrich Inc. (Merck KGaA, Darmstadt, Germany) (15 g/L) were used. The bacterial growth was monitored via optical density (OD) measurements.

\subsection{Monitoring Biosurfactant Production}

Preliminary tests were carried out (microcosm experiments) to find the most suitable incubation period for maximum biosurfactant production by $A$. borkumensis $S K 2$, using HOF as substrates. 
The cultivation volume was $200 \mathrm{~mL}$ (190 mL ONR7a + $10 \mathrm{~mL}$ NP), in which $1 \mathrm{~g}$ HOF-1 and the bacteria $A$. borkumensis SK2, with initial concentration $1 \times 10^{7}$ colony forming units per $\mathrm{mL}(\mathrm{CFU} / \mathrm{mL})$, were added. The nutrients $\mathrm{N}$ and $\mathrm{P}$ followed the ratio $\mathrm{C}: \mathrm{N}: \mathrm{P}$ equal to 100:10:1. The cultures were incubated at $20^{\circ} \mathrm{C}$ and agitated at $120 \mathrm{rpm}$ on an orbital shaker. This experiment took place for 30 days, and the biosurfactant concentration was estimated every 4 days. The samples taken each time had volume equal to $20 \mathrm{~mL}$. The procedure that took place for the biosurfactant extraction was solvent extraction for rhamnolipids, according to the method used by Smyth et al. [23]. The solvent used for the extraction was Ethyl acetate (Merck KGaA, Darmstadt, Germany). During this experiment, the bacteria proved to dissolve the HOF-1 into the water column after 22 days of incubation. This made us use the even heavier oil fraction (HOF-2) to reach the goal of producing $\mathrm{BS}$ without substrate impurities.

HOF-2 is a heavy oil fraction with even less solubility than HOF-1. The volume of the cultivations was $300 \mathrm{~mL}$ of ONR7a, the 'smart carbon' source (HOF-2) was at a percent of 0.5\% (1.5 gr HOF-2), and the added nutrients followed the ratio of C:N:P equal to 100:10:1. The initial bacterial concentration of $A$. borkumensis SK2 was $1 \times 10^{7} \mathrm{CFU} / \mathrm{mL}$. The cultures were incubated at $20^{\circ} \mathrm{C}$, and, in an orbital shaker, agitated at $120 \mathrm{rpm}$. This experiment took place for 20 days, and the biosurfactant concentration was estimated every 5 days. The samples taken each time had volume equal to $20 \mathrm{~mL}$. The procedure that took place for the biosurfactant extraction was solvent extraction for rhamnolipids, according to the method used by Smyth et al. [23]. The solvent used for the extraction was Ethyl acetate (Merck KGaA, Darmstadt, Germany).

\subsection{BS Detection-Thin Layer Chromatography}

During previously reported results, detection and characterization techniques used to confirm the BS chemical composition were thin layer chromatography (TLC), Fourier transform infra-red spectrometry (FT-IR) and liquid chromatography coupled with mass spectrometry (LC-MS) [19]. Alcanivorax borkumensis SK2 produced mostly rhamnolipids. During our current investigation, TLC was carried out to confirm rhamnolipid production. Biosurfactants produced by Alcanivorax borkumensis SK2 were compared to a standard rhamnolipid mixture of Rha-C10-C10 and Rha-Rha-C10-C10 (R-95 RL95\%, Sigma-Aldrich Inc., Merck KGaA, Darmstadt, Germany). Silica gel TLC plates were used according to the method by Smyth et al. for rhamnolipid detection. The developing solvent system was chloroform:methanol:acetic acid (6.5:1.5:0.2 v/v/v), and the visualization solvent was anthrone reagent, sulfuric acid:water:anthrone (63:25:0.125 v/v/w) [23]. The visualized spots of each sample were compared to the standard ones. On visualization, the green colored spot nearer the point of origin corresponded to the dirhamnolipids, while the one further from the point of origin represented the monorhamnolipids [23]. To compare the samples, the RF value was calculated. This value is equal to the distance from the origin point where the crude extract was initially placed until the point where the spot emerged, divided by the total distance the solvent made on the plate.

\subsection{Bioreactor Preparation}

The bioreactor was filled with 3.3 L ONR7a and sterilized in an autoclave. Solution (NP) of the nutrients $\mathrm{KNO}_{3}$ and $\mathrm{KH}_{2} \mathrm{PO}_{4}$ was sterilized separately and added afterward to the bioreactor. As for the carbon substrate, the HOF-2 was first sterilized and warmed up at approximately $250{ }^{\circ} \mathrm{C}$ and spread on sterilized nets with a surface of $2 \times 2 \mathrm{~cm}^{2}$. The total surface of the nets placed into the bioreactor (by taking into consideration both sides of the nets) was $320 \mathrm{~cm}^{2}$ approximately. Lastly, the bacteria A. borkumensis SK2 was added to the bioreactor (cultivated separately in a beaker). Then, $50 \mathrm{~mL}$ of the cultivation with $2.52 \times 10^{11}$ CFU (after 6 days of incubation in Zobell Marine 2216, $40.25 \mathrm{~g} / \mathrm{L}$ ) were centrifuged for $20 \mathrm{~min}$ at $7000 \mathrm{rpm}$, and the resulting pellet was cleaned with ONR7a and centrifuged again. This process took place 3 times. The pellet was diluted in a small quantity of sterilized ONR7a and added to the bioreactor. The initial concentration of 
bacteria in the bioreactor was $7.6 \times 10^{7} \mathrm{CFU} / \mathrm{mL}$. The operation volume of the bioreactor was $3.3 \mathrm{~L}$, the temperature was $20^{\circ} \mathrm{C}$, the air flow was $50 \mathrm{~L} / \mathrm{h}$, the dissolved oxygen was $35 \%$ and the stirring rate was $150 \mathrm{rpm}$.

\subsection{Bioreactor Operation}

The physicochemical parameters and the operation conditions of a bioreactor are of high importance for the production of BSs. Parameters such as temperature, stirring, kind of carbon source and nutrition concentrations have been shown to have great effect on BS production [7]. During the bioreactor operation, the physical conditions were the following: temperature, $20{ }^{\circ} \mathrm{C}$; mixing, $150 \mathrm{rpm}$; air flow, $50 \mathrm{~L} / \mathrm{h}$; dissolved oxygen, $35 \%$; and total culture volume, $3.3 \mathrm{~L}$.

At the first stage of the bioreactors operation, the reactor was operated as a batch reactor for 10 days. During this first period, the concentration of the biosurfactants reached its highest point. At day 10, the second stage of the bioreactors operation, as sequenced semi-batch reactor, started. At that point, $60 \%$ of the volume of the bioreactor was removed and replaced with fresh ONR7a with nutrients NP. By removing $60 \%$ of the cultivation, the concentration of the bacteria is halved, but the order of magnitude does not change. As for the carbon source, it was not removed, because it was immobilized on the nets. To estimate the concentration of the biosurfactants, three samples of $35 \mathrm{~mL}$ were taken and examined with solvent extraction according to Smyth et al. [23]. The aim was to find the most suitable timeframe, in which the system of the bioreactor would reach the maximum BS concentration again. For this, samples were taken and examined after several timeframes (after 1 day, 3 days, 5 days, 6 days and 7 days of operation). Until day 6 , the concentration was increasing and reached its highest value; after that, it decreased again at day 7. Sampling was performed in triplicates, and the volume of each sample was $35 \mathrm{~mL}$.

\subsection{Baffled Flask Test-Biosurfactant Efficiency Test}

In order to measure the oil dispersion efficiency of the BS produced, they were tested by the baffled flask test (BFT) protocol, according to the US Environmental Protection Agency (EPA) approved efficiency test for screening the effectiveness of dispersant products in the laboratory [24]. The experiment took place in room temperature approximately $20^{\circ} \mathrm{C}$. The pure biosurfactant extract is honey-like and could not be used as it was, so it was first diluted in soybean oil. Four $(0 \%, 5 \%, 7.5 \%$ and $15 \% w / v)$ different BS concentrations were tested.

Baffled flasks were filled with $120 \mathrm{~mL}$ saline medium, $100 \mu \mathrm{L}$ Iranian light crude oil and $4 \mu \mathrm{L}$ of biosurfactant diluted in soybean oil. The Baffled flasks were stirred for $10 \mathrm{~min}$ at $200 \mathrm{rpm}$, followed by a $10 \mathrm{~min}$ resting period. The two first $\mathrm{mL}$ of the flask content were discarded, and $30 \mathrm{~mL}$ from each flask were selected for further handling. The crude oil was extracted with liquid-liquid extraction. The solvent used was dichloromethane $(5 \mathrm{~mL}$, 3 times) (DCM Suprasolv ${ }^{\circledR}$, Merck KGaA, Darmstadt, Germany). The extracted sample was supplemented with DCM SupraSolv until the total volume was $20 \mathrm{~mL}$. The sample absorbance was directly measured with a UV-VIS spectrophotometer at $340 \mathrm{~nm}, 370 \mathrm{~nm}$ and $400 \mathrm{~nm}$. The results were compared to the calibration curve in Figure A1, and the efficiency was determined according to the BFT test protocol equations [24] (Appendix A).

\subsection{Bioremediation Test}

The biodegradation of crude oil with the use or not of biosurfactants was determined by a 28-day bioremediation test. Triplicate treatments were made with seawater, $0.5 \mathrm{v} / \mathrm{v} \%$ Iranian crude oil and nutrients $\mathrm{N}$ and $\mathrm{P}$ in C:N:P ratio 100:10:1, respectively. The time points that the hydrocarbon concentrations were determined were at time zero, day 7 and day 28. The hydrocarbon analysis was done with gas chromatography-mass spectrometry (GC-MS), according to the method described below.

For easier handling of the BSs produced during our bioreactor experiment, we had to dilute them first. For this purpose, we used two kinds of solvents, distilled water $\left(\mathrm{dH}_{2} \mathrm{O}\right)$ 
and soybean oil (SOY). The BS solubility in water was very low and allowed us to produce a $0.4 \% w / v$ BS-in- $\mathrm{dH}_{2} \mathrm{O}$ agent. The BS solubility in soybean oil was much higher, and we decided to produce a $15 \% w / v$ BS-in-SOY agent. Due to the significant difference in the concentration of the BSs in our agents, we decided to use higher quantity of the BS-in- $\mathrm{dH}_{2} \mathrm{O}$ agent than the BS-in-SOY agent during the experiments. We used $0.5 \mathrm{~mL}$ of BS-in- $\mathrm{dH}_{2} \mathrm{O}$ agent and $33.3 \mu \mathrm{L}$ of BS-in-SOY agent in each vial with $10 \mathrm{~mL}$ of sea water. The final quantity of BS was $2 \mathrm{mg}$ pure BS for the BS-in- $\mathrm{dH}_{2} \mathrm{O}$ experiment and $5 \mathrm{mg}$ of pure BS for the BS-in-SOY experiment. Sea water was collected from Agios Onoufrios bay, Akrotiri, Chania, Greece.

\subsection{Hydrocarbon Extraction and GC-MS Analysis}

Liquid-liquid extraction was used to obtain the hydrocarbons extract, free from the culture medium. The organic compounds were extracted using equal volumes of DCM Suprasolv $^{\circledR}$ (Merck KGaA, Darmstadt, Germany) (3× for each extraction) in $100 \mathrm{~mL}$ separatory funnels. The funnels were shaken manually to assist the dissolution of the organic compounds. Solvent removal was performed on a rotary evaporator, and the extracts were transferred to $4 \mathrm{~mL}$ vials with DCM Suprasolv ${ }^{\circledR}$ and were concentrated under nitrogen flow. The extracts were eluted through SPE columns (Bond Elute TPH, Agilent Technologies, Inc., Santa Clara, CA, USA) and separated in saturated and aromatic hydrocarbon fractions with n-hexane Suprasolv ${ }^{\circledR}$ (Merck KGaA, Darmstadt, Germany) and DCM Suprasolv ${ }^{\circledR}$, respectively. The saturated and aromatic fractions were analyzed using an Agilent GC-MS HP 7890/5975C system, with an Agilent HP-5MS 5\% phenyl methyl siloxane column $(60 \mathrm{~m} \times 250 \mu \mathrm{m} \times 0.25 \mu \mathrm{m})$. The Oil Analysis Standard (Absolute Standards Inc. ${ }^{\circledR}$, Hamden, CT, USA), containing 44 compounds, and a $17 \mathrm{a}(\mathrm{H}), 21 \mathrm{~b}(\mathrm{H})$-hopane (Chiron $\mathrm{AS}^{\circledR}{ }^{\circledR}$, Trondheim, Norway) were used for calibration. Theoil analysis standard consists of normal alkanes from $\mathrm{C} 10$ to $\mathrm{C} 35$, pristane and phytane and 16 polycyclic aromatic hydrocarbons (PAHs) (naphthalene, anthracene, phenanthrene, fluorene, pyrene, dibenzothiophene, fluoranthene, chrysene, benzo(a)pyrene, benzo(b)fluoranthene, benzo(e)pyrene, benzo(k)fluoranthene, perylene, indeno(g,h,i)pyrene, dibenzo(a,h)anthracene and benzo(1,2,3-cd)perylene).

\section{Results}

\subsection{Alcanivorax borkumensis SK2 Cultivation}

The bacteria A. borkumensis $S K 2$ was cultivated in microcosms with the same nutrients as in the bioreactor, and the growth curve was produced. The medium was ONR7a, HOF-2 was the carbon source, and NP dilution was added as to have C:N:P equal to 100:10:1. As observed in Figure 1, the OD logarithmically increases, reaching the stationary phase on day 6.

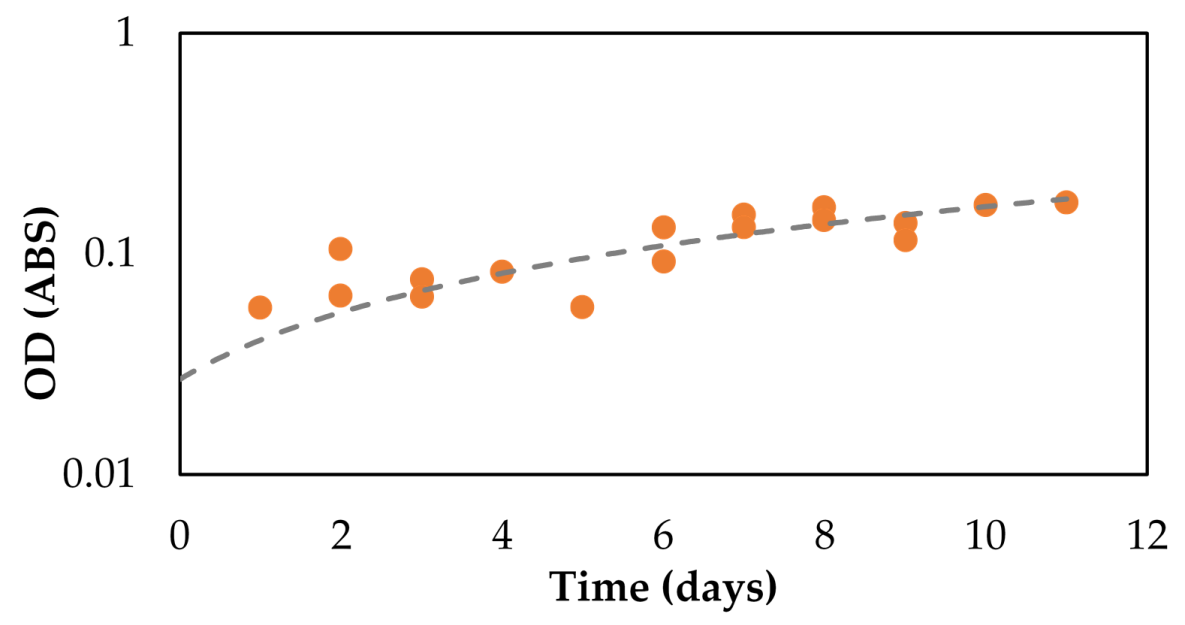

Figure 1. Growth curve of Alcanivorax borkumensis SK2 in ONR7a with HOF-2 and N and P nutrients. Optical Density (OD) vs. Time. 


\subsection{Biosurfactant Production}

Alcanivorax borkumensis SK2 was cultured with HOF-1 and HOF-2 as carbon sources. This bacterium is known for its glycolipid production as well as its hydrocarbon degrading capability [19]. As for the carbon source, HOF is a very hard solid with reduced ability to be dissolved in water. The maximum BS concentration produced by A. borkumensis SK2, according to Figure 2a, is $52.5 \mathrm{mg} / \mathrm{L}$ and is reached after 22 days of incubation, with HOF-1 as the substrate. After 26 days of incubation, the HOF-1 was dissolved into the water column, and the final BS product had substrate impurities. By using HOF-2 as substrate, according to Figure $2 \mathrm{~b}, A$. borkumensis SK2 produces a maximum of $16 \mathrm{mg} / \mathrm{L}$ BS in 10 days of incubation. This concentration is much lower, but the HOF-2 does not dissolve into the water column, not even after a month of incubation.

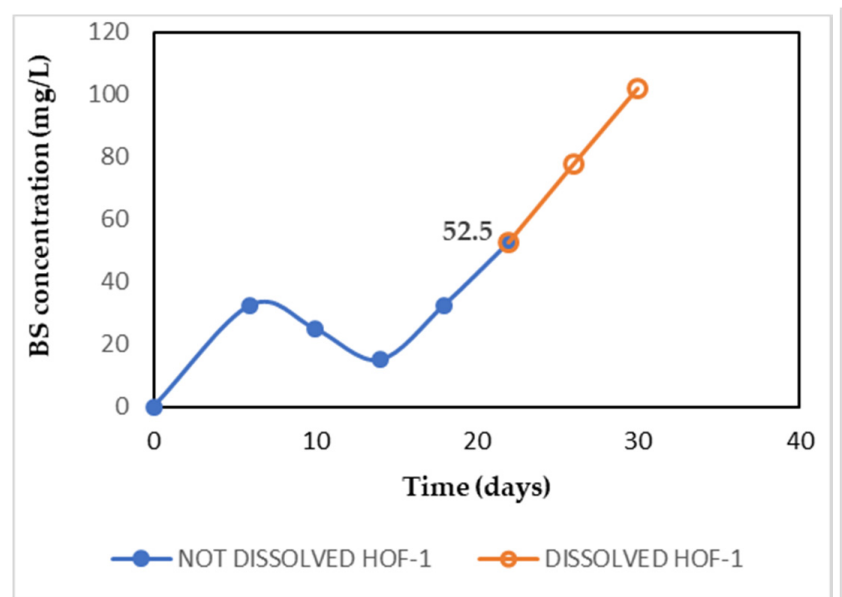

(a)

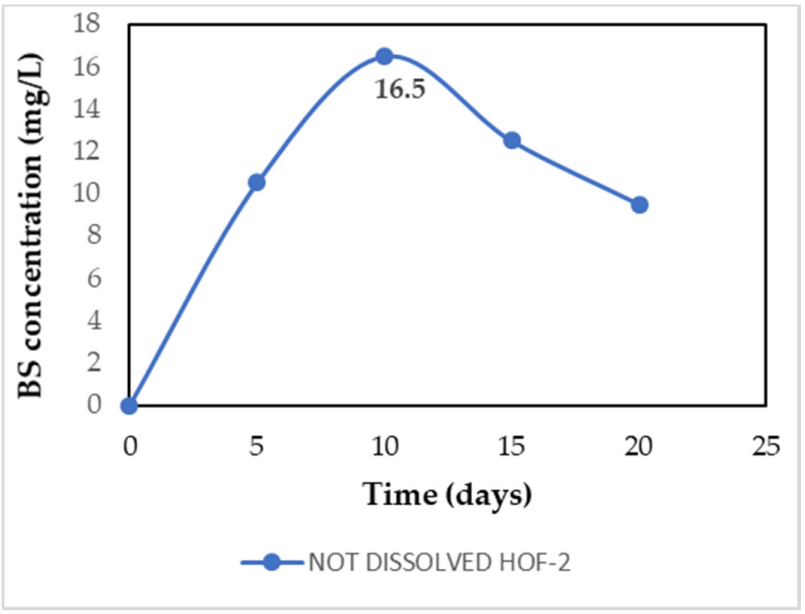

(b)

Figure 2. (a) Biosurfactant production by A. borkumensis SK2 in ONR7a with HOF-1 as carbon source and N and P nutrients (filled dots $\bullet$ ); $52.5 \mathrm{mg} / \mathrm{L}$ is the maximum amount of BS reached without impurities in the product; after that, the product is contaminated by the carbon source (empty dots o). (b) Biosurfactant production by A. borkumensis SK2 in ONR7a with HOF-2 as the carbon source and $\mathrm{N}$ and P nutrients.

\subsection{BS Detection-Thin Layer Chromatography}

TLC took place to compare the BS produced by Alcanivorax borkumensis SK2 with a rhamnolipid standard $95 \%$. The rhamnolipid standard had two different substances, monorhamnolipids (Rha-C10-C10) and dirhamnolipids (Rha-Rha-C10-C10). On the TLC plate of the standard sample, two spots emerged, one for each substance, while on the BS samples ones, four spots emerged. This means that four substances were included in the produced glycolipid mixture (BS). From those, two were detected in similar position as the standard sample, shown in Table 1. The RF value was used for comparison and is equal to the distance from the point of origin of the solvent until the spot, divided to the total distance the solvent is going through on the silica plate.

Table 1. RF values of standard rhamnolipids $95 \%$ and BS produced by Alkanivorax borkumensis SK2.

\begin{tabular}{ccccc}
\hline Sample & Dirhamnolipid & Monorhamnolipid & Unknown & Unknown \\
\hline RF Standard 95\% & 0.30 & 0.67 & & \\
RF BS by Alcanivorax & 0.29 & 0.61 & 0.53 & 0.77 \\
borkumensis SK2 & 4.65 & 9.03 & & \\
\% deviation & & & \\
\hline
\end{tabular}

TLC results show that the BS mixture contains mono- and dirhamnolipids but also two more unknown lipids. The deviation of the RF values for the mono- and di-rhamnolipids of our BS sample from the standard one was $9.03 \%$ and $4.65 \%$, respectively. 


\subsection{Sequencing Batch Reactor, SBR Cycle}

A bioreactor (Bioengineering AG, Switzerland) was used for biosurfactant production by the bacteria $A$. borkumensis SK2 in ONR7a, with HOF-2 as the carbon source. The first period of the bioreactor was a 10-day batch period, until the maximum BS concentration was reached (Figure 3). Then, $60 \%$ of the cultivation's volume was replaced with fresh ONR7a and NP nutrients, and the bioreactor operated until the maximum concentration of BS was reached again. In other words, the aim was to find the best sequencing batch reactor (SBR) operation period for maximum biosurfactant production in minimum time. In order to estimate how many days the system needed to reach again the maximum biosurfactant concentration, random samples were taken frequently enough to identify the time needed to replenish the BS concentration to the value detected from the preliminary results. The first time we removed $60 \%$ of the cultivation volume was at Day 4 (4-day cycle), and the second time at Day 11 (6-day cycle). According to Figure 3, the most suitable operation time is 6 days, and the maximum BS concentration is $22 \mathrm{mg} / \mathrm{L}$ (which is improved by $28 \%$ compared to the preliminary microcosm results). In Figure 3 , the line $\mathrm{BS} \mathrm{mg} / \mathrm{L}$ represents the concentration of biosurfactants at each moment. Max BS mg/L represents the concentration of biosurfactants at the moment before the volume of the bioreactor was reduced by $60 \%$. Min BS mg/L represents the moment that the bioreactor was refilled with fresh ONR7a and NP.

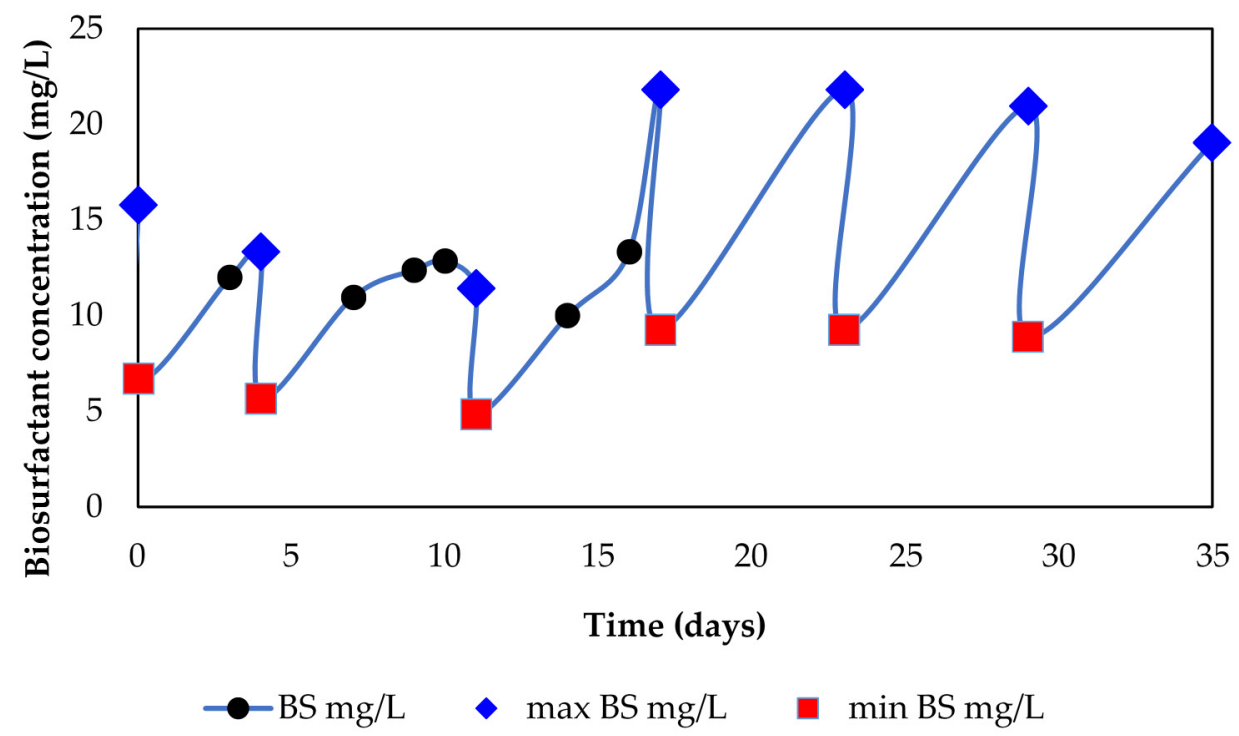

Figure 3. Biosurfactant concentration cycle in sequencing batch reactor. Time zero is after a 10-day batch operation period. Max BS represents the BS concentration just before removing $60 \%$ of the cultures volume (rhombus). Min BS represents the BS concentration just after adding new ONR7a and nutrients to fill up the bioreactor (square). Black circles represent sampling points in between the min and max values.

\subsection{Biosurfactant Dispersion Efficiency Test}

According to the BFT and Figure 4, the BS 5\%, 7.5\% and 15\% $w / v$ diluted in soybean oil are effective in crude oil dispersion, and the dispersion efficiency of soybean oil was increased by $25.85 \%, 74.85 \%$ and $77.76 \%$, respectively. 


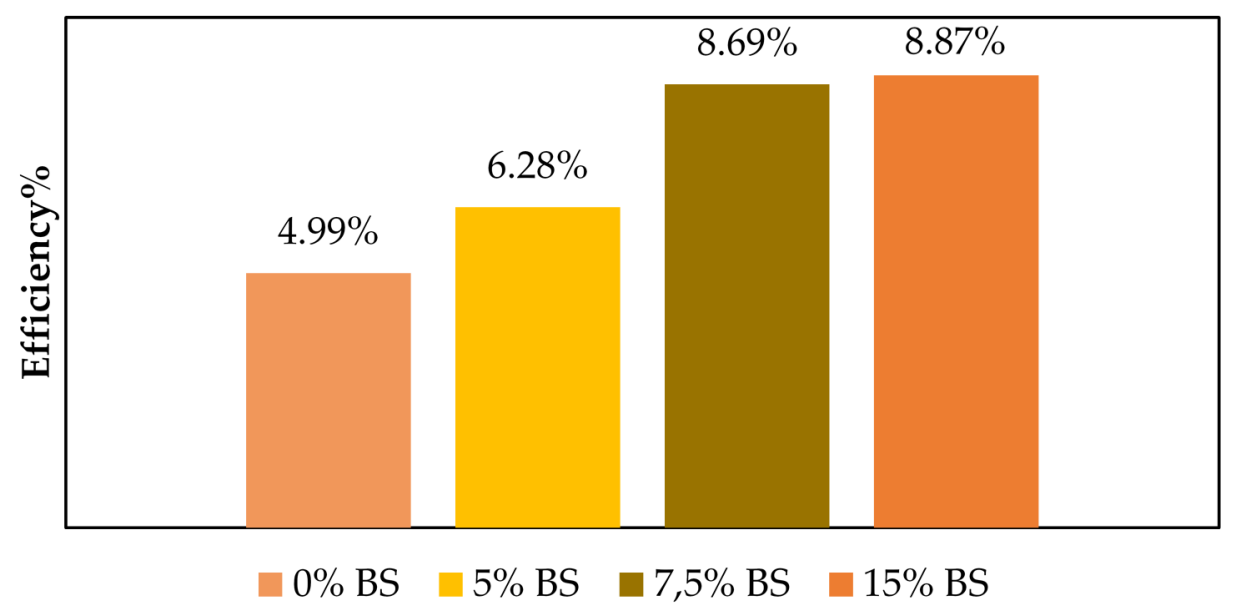

Figure 4. BFT efficiency test of BS-in-SOY agent with BS produced by Alcanivorax borkumensis SK2. The concentration of BS diluted in soybean oil where $0 \%, 5 \%, 7.5 \%$ and $15 \% w / v$.

\subsection{Bioremediation Test}

In order to determine the BS efficiency in the biodegradation process, a bioremediation set of experiments was done. The results revealed the BS as well as the solvent role in the bioremediation process. The saturated hydrocarbons concentration, with biosurfactants dissolved in both solvents, does not have a significant decrease until day 7 (Figures A2 and A3), but is reduced significantly until day 28 (Figures 5 and 6). Furthermore, Figure 7 shows that soybean oil has been a hindering agent in the biodegradation of crude oil. The average percentage of reduction of saturated hydrocarbons in 28 days is $52.18 \%$ for BS dissolved in distilled water $(0.4 \% w / v \sim 0.5 \mathrm{~mL}$ BS-in-water $\sim 2 \mathrm{mg}$ pure BS/10 mL seawater) and $29.45 \%$ for BS dissolved in soybean oil (15\% $w / v \sim 33.3 \mu \mathrm{L}$ BS-in-soybean oil $\sim 5 \mathrm{mg}$ pure BS/10 $\mathrm{mL}$ seawater).

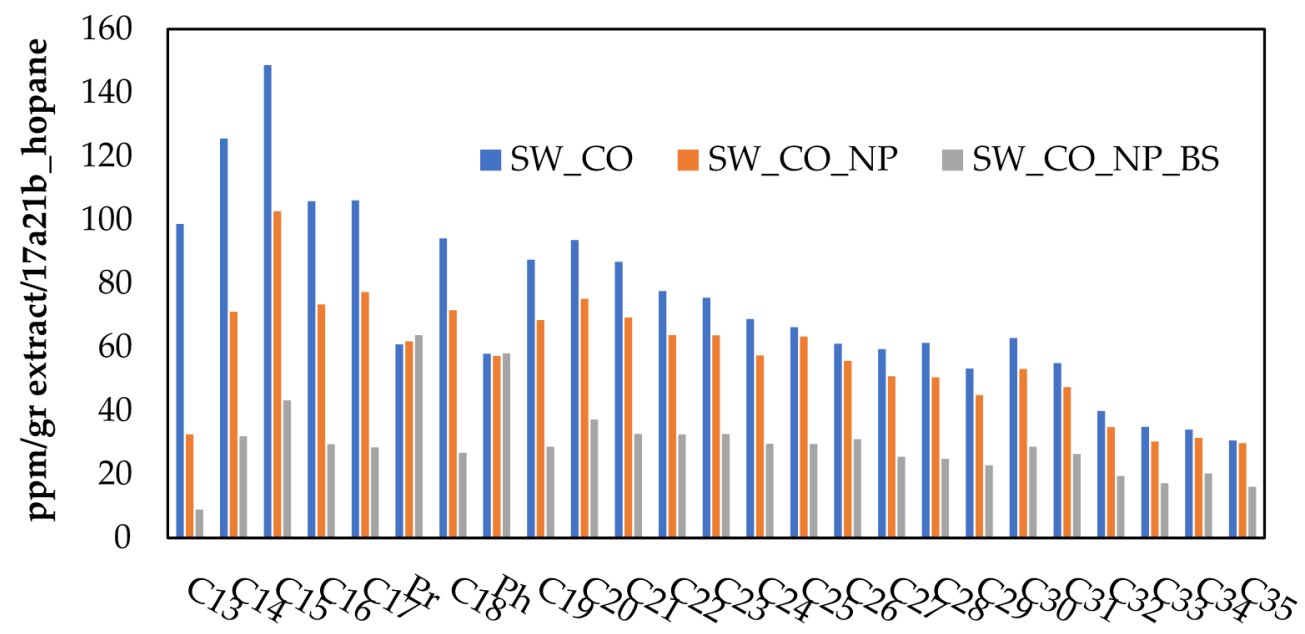

Figure 5. Bioremediation test results. Saturated hydrocarbons concentration after 28 days of bioremediation ( $\mathrm{Cx}$ are the saturated hydrocarbons, $\mathrm{x}$ is the number of carbons in the molecule, Pr: pristane and Ph: phytane). (a) SW_CO: Sea water with crude oil. (b) SW_CO_NP: Sea water, crude oil and $\mathrm{N}$ and P nutrients. (c) SW_CO_NP_BS: Sea water, crude oil, $\mathrm{N}$ and $\mathrm{P}$ nutrients and BS-in-dH $\mathrm{H}_{2} \mathrm{O}$ $0.4 \% w / v$. 


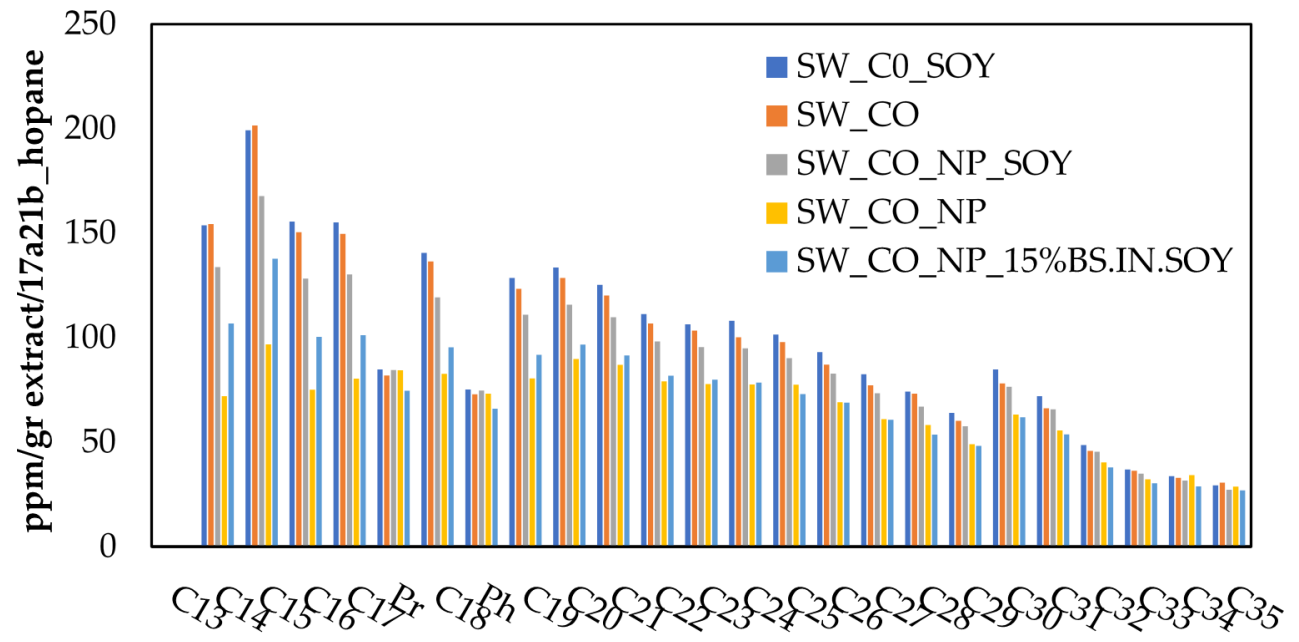

Figure 6. Bioremediation test results. Saturated hydrocarbons concentration after 28 days of bioremediation ( $\mathrm{Cx}$ are the saturated hydrocarbons, $\mathrm{x}$ is the number of carbons in the molecule, Pr: pristane and Ph: phytane). (a) SW_CO: Sea water with crude oil. (b) SW_CO_SOY: Sea water, crude oil and soybean oil (c). SW_CO_NP: Sea water, crude oil and N and P nutrients. (d) SW_CO_NP_SOY: Sea water, crude oil, N and P nutrients and soybean oil. (e) SW_CO_NP_15\% BS.IN.SOY: Sea water, crude oil, $\mathrm{N}$ and P nutrients and BS-in-SOY agent $15 \% w / v$.

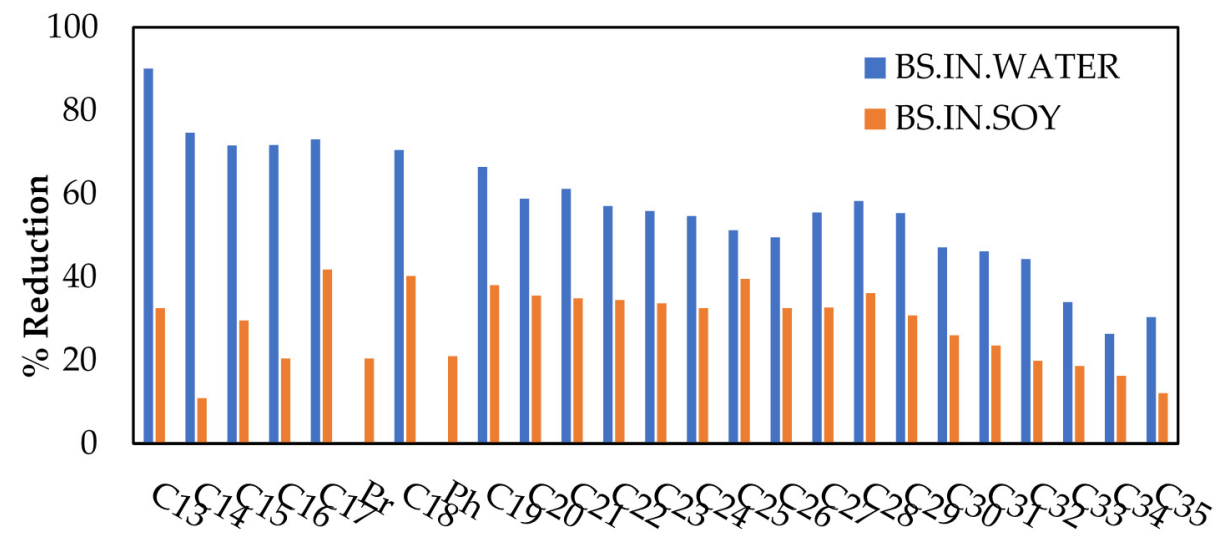

Figure 7. Bioremediation test. Comparing percentages of reduction of Saturated Hydrocarbons after 28 days of bioremediation ( $\mathrm{Cx}$ are the saturated hydrocarbons, $\mathrm{x}$ is the number of carbons in the molecule, Pr: pristane and Ph: phytane). Comparing results of cultivations with sea water from Agios Onoufrios and crude oil plus BS-in- $\mathrm{dH}_{2} \mathrm{O}$ agent $(0.4 \% w / v)$ and BS-in-SOY agent $(15 \% w / v)$.

As for the aromatic hydrocarbons, they do not show any significant change in concentration in the 28-day experiment (Figures A4-A7).

\section{Discussion}

Biosurfactant production by strain Alcanivorax borkumensis SK2 using heavy oil fractions as carbon source was investigated. The aim of this investigation was to produce BS without any impurities from the substrate. HOF-2 as a 'smart' carbon source proved to be nonsoluble in the aqueous phase, providing a high-purity BS product. By immobilizing the HOF-2 carbon source on sterilized nets, we succeeded in its easy handling and removal from the liquid face. The bacteria used the carbon source to produce biosurfactants without being able to dissolve it, and in this way, they released the biosurfactants without any oil impurities in the liquid. The BS produced was identified by TLC, compared with a rhamnolipid mixture standard. The final BS product is a honey-like substance consisting of mono- and di-rhamnolipids and two more glycolipids. 
The BSs were further investigated in their ability to degrade crude oil. For better handling, the BSs were dissolved in water and soybean oil. BSs dissolved in water enhanced bioremediation, and the average percentage of reduction of saturated hydrocarbons by day 28 was $52.18 \%$. When soybean oil was used as solvent, the saturated hydrocarbons decreased by $29.45 \%$. The mass reduction of aromatic hydrocarbons was negligible after 28 days of experiment in both cases.

The maximum BS concentration produced by A. borkumensis SK2 in the bioreactor with HOF-2 as the carbon source was about $\sim 20 \mathrm{mg} / \mathrm{L}$. The stable conditions of the bioreactor improved the BS production by $A$. borkumensis $S K 2$ by $4 \mathrm{mg} / \mathrm{L}$, approximately, comparing it with the preliminary tests. Nevertheless, comparing those concentrations with literature data, a fast conclusion would be that the concentration is too low. For instance, a $46 \mathrm{~g} / \mathrm{L}$ rhamnolipids production yield was performed by P. aeruginosa UFPEDA 614 when a solidstate cultivation with glycerol, sunflower seed meal and sugarcane bagasse was used [6]. The unique outcome of this research is that the BS product is clean from substrate impurities and can be extracted using a simple liquid-liquid extraction, eliminating the money and time-consuming process of column chromatography purification.

\section{Conclusions}

A biobased surfactant is produced by marine hydrocarbon-degrading bacteria. Aiming at the growing biosurfactant market, which includes oil spill response, enhanced oil recovery, detergents, personal hygiene and cosmetics, a novel scaled up production scheme (Figure A8) is proposed that enables easy separation of the biosurfactant mixture from the growth media. Due to the 'smart' carbon source used, the final product is free from substrate impurities. The handling of the HOF substrate-smart source is the most challenging part in this proposed production process. Moreover, in order for this scheme to be economically feasible, a number of SBR reactors have to be connected in line.

It would be interesting to further investigate whether the addition of a light hydrocarbon, for instance, dodecane, would enhance the biosurfactant production ability of the strain, and thus the yield of the microbial strain in BS, or would hinder the process.

\section{Patents}

Antoniou, E.; Kalogerakis, N.; Technological Educational Institute of Eastern Macedonia and Thrace; Technical University of Crete; Production Method of high-purity Biosurfactants from marine bacteria that biodegrade heavy crude oil byproducts, \#1009585, Hellenic Industrial Property Organisation (OBI).

Author Contributions: Conceptualization, E.A. and N.K.; methodology, E.A.; validation, A.M., E.A. and N.K.; formal analysis, A.M.; investigation, A.M.; resources, N.K.; data curation, A.M. and E.A.; writing-original draft preparation, A.M.; writing-review and editing, E.A. and A.M.; supervision, E.A.; project administration, E.A.; funding acquisition, E.A. and N.K. All authors have read and agreed to the published version of the manuscript.

Funding: This research was funded by Stavros Niarchos Foundation (SNF), Funding Year 2015, 'Assisting young scientists in prototyping innovative products by using cutting-edge technology', and the FP-7 project. Integrated Biotechnological Solutions for Combating Marine Oil Spills—KILL•SPILL contract No. 312139.

Data Availability Statement: The data presented in this study are available on request from the corresponding author.

Conflicts of Interest: The authors declare no conflict of interest. The funders had no role in the design of the study; in the collection, analyses, or interpretation of data; in the writing of the manuscript; or in the decision to publish the results. 


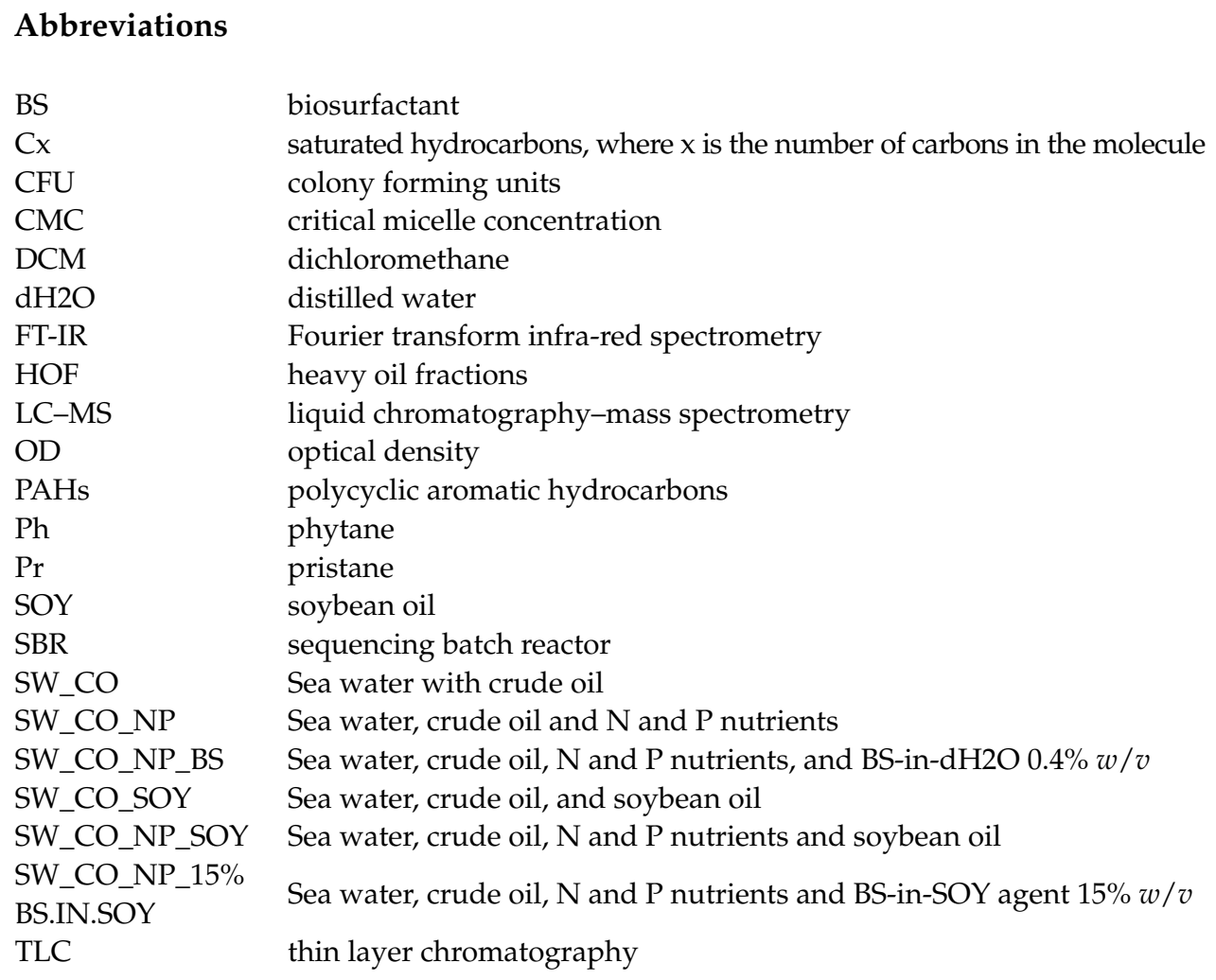

\section{Appendix A}

\section{BFT TEST Protocol}

In order to determine the oil dispersed in the water phase using UV-VIS technique, we developed the calibration curve of known concentrations of oil in saline medium according to the procedure described in the EPA BFT TEST (George, 2006). A standard solution of oil (Iranian light oil) in DCM was prepared for calibrating the UV-VIS spectrophotometer$5 \mathrm{~mL}$ of the oil with $45 \mathrm{~mL}$ DCM (8.4\%wt solution). Specific volumes of 5, 10, 25, 50, 100 and $1000 \mu \mathrm{L}$ of oil-DCM stock were added to synthetic sea water $(30 \mathrm{~mL})$ in a separatory funnel and extracted three times with DCM $(5 \mathrm{~mL})$. The final DCM extract was adjusted to $20 \mathrm{~mL}$ with DCM and transferred to a $20 \mathrm{~mL}$ glass vial with a Teflon seal cap, mixed and stored in a refrigerator at $4 \pm 2{ }^{\circ} \mathrm{C}$. Based on the density $(0.84 \mathrm{~g} / \mathrm{mL})$ and the amount of oil added, the concentration of the solutions was calculated. The samples were measured in UV-VIS spectrophotometer, and the results are depicted in Figure A1.

The BFT samples were similarly analyzed. The experimental sample extracts and the standard solutions prepared were allowed to equilibrate at the laboratory temperature. First, the blank solution (DCM) and then the standard solutions were measured, and the absorbance values were noted at wavelengths of 340, 370 and $400 \mathrm{~nm}$. After this, the experimental samples were inserted.

The area under the absorbance vs. wavelength curve of the experimental samples between wavelengths 340 and $400 \mathrm{~nm}$ was calculated using the following equation according to the trapezoidal rule:

$$
\text { Area }=\left[\left(\mathrm{Abs}_{340}+\mathrm{Abs}_{370}\right) \times 30\right] / 2+\left[\left(\mathrm{Abs}_{370}+\mathrm{Abs}_{400}\right) \times 30\right] / 2
$$

The dispersant efficiency was determined by Equation (A2) based on the ratio of oil dispersed to the total oil added to the system:

$$
\mathrm{Eff} \%=\text { Total oil Dispersed } / \rho_{\text {oil }} \times \mathrm{V}_{\text {oil }} \times 100
$$

where: 
$\rho_{\text {oil }}=$ density of the specific test oil, $\mathrm{g} / \mathrm{L}$

$\mathrm{V}_{\text {oil }}=$ Volume $(\mathrm{L})$ of oil added to the test flask $(100 \mu \mathrm{L})$

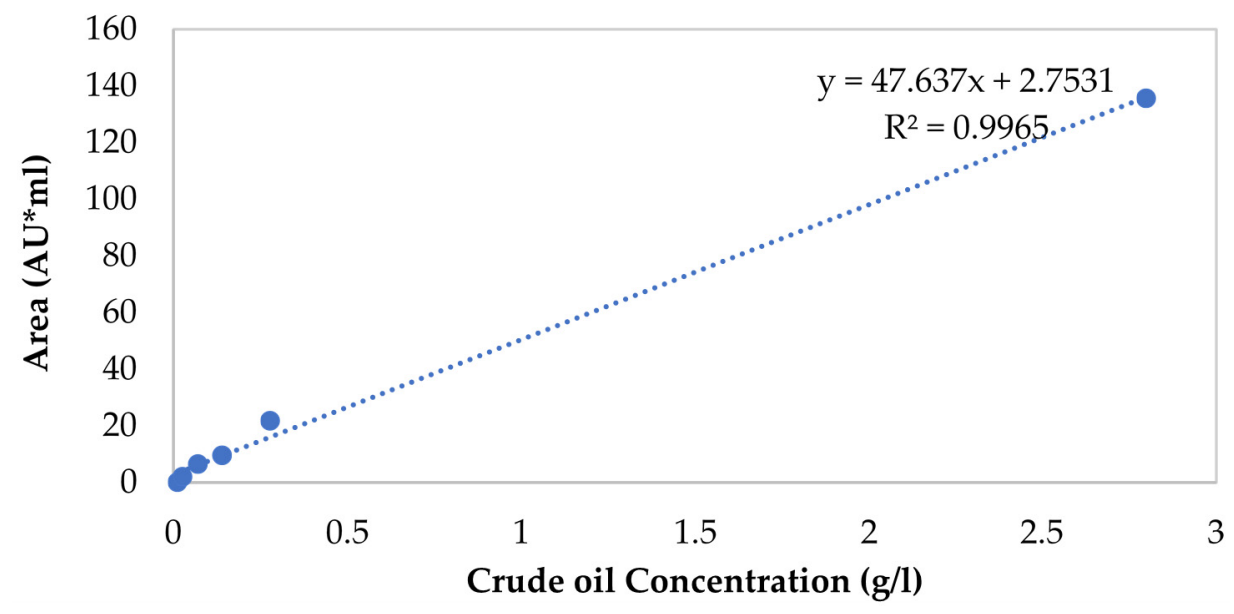

Figure A1. Calibration curve of dissolved crude oil in saline water.

\section{Appendix B}

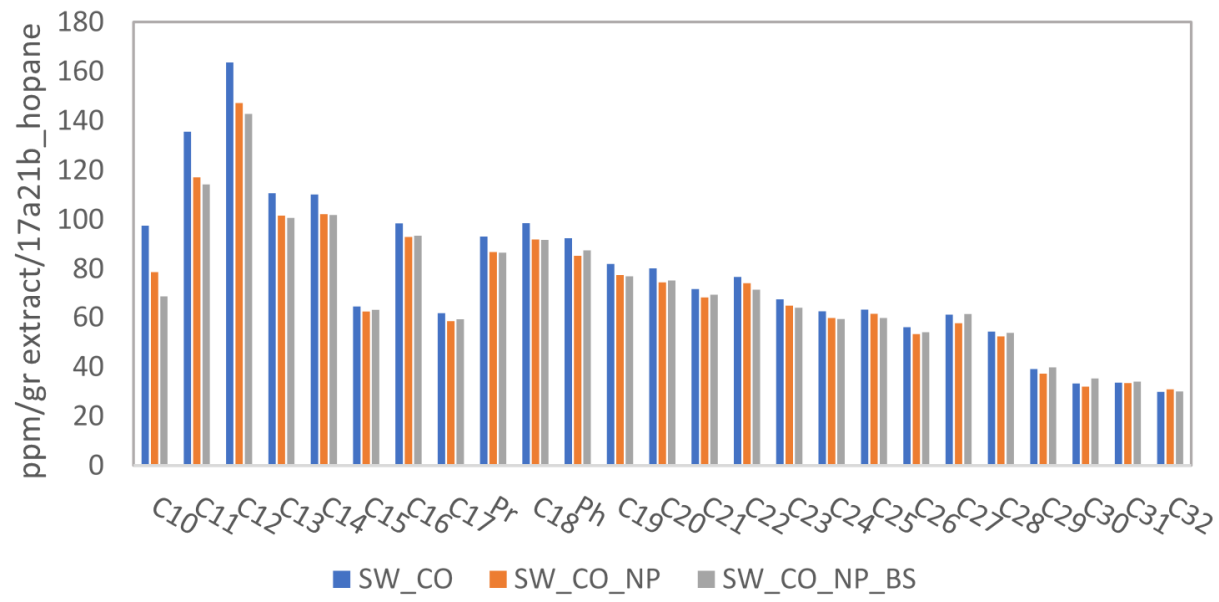

Figure A2. Bioremediation test results. Saturated hydrocarbons concentration after 7 days of bioremediation. (a) SW_CO: Sea water with crude oil. (b) SW_CO_NP: Sea water, crude oil and N and P nutrients. (c) SW_CO_NP_BS: Sea water, crude oil, N and P nutrients and BS-in- $\mathrm{dH}_{2} \mathrm{O} 0.4 \%$ $w / v$. (Cx are the saturated hydrocarbons, $\mathrm{x}$ is the number of carbons in the molecule, Pr: pristane and $\mathrm{Ph}$ : phytane). 


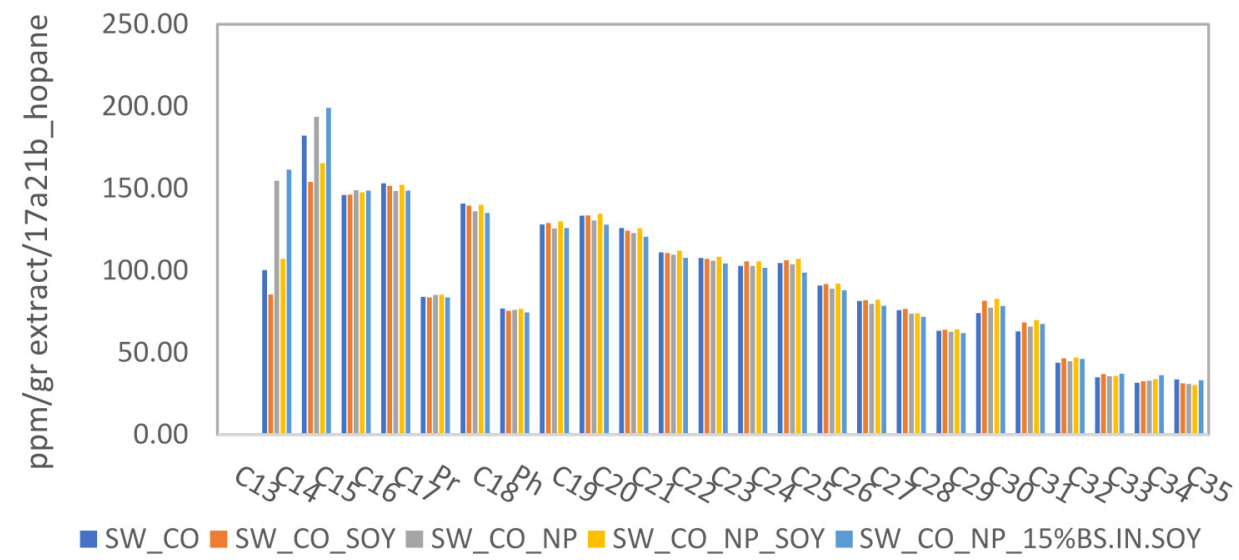

Figure A3. Bioremediation test results. Saturated hydrocarbons concentration after 7 days of bioremediation. (a) SW_CO: Sea water with crude oil. (b) SW_CO_SOY: Sea water, crude oil and soybean oil. (c) SW_CO_NP: Sea water, crude oil and N and P nutrients. (d) SW_CO_NP_SOY: Sea water, crude oil, N and P nutrients and soybean oil. (e) SW_CO_NP_15\%BS.IN.SOY: Sea water, crude oil, $\mathrm{N}$ and $\mathrm{P}$ nutrients and BS-in-SOY agent 15\% w/v. (Cx are the saturated hydrocarbons, $\mathrm{x}$ is the number of carbons in the molecule, Pr: pristane and Ph: phytane).

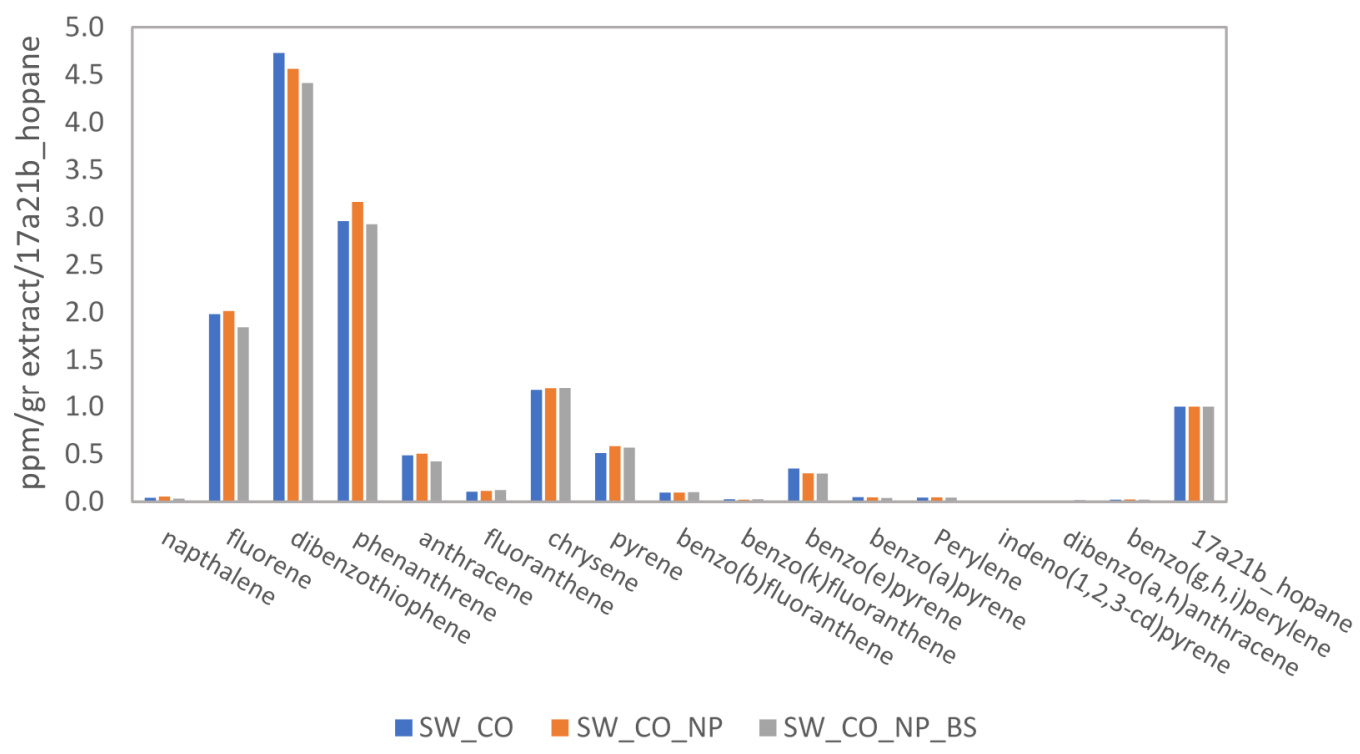

Figure A4. Bioremediation test results. Aromatic hydrocarbons concentration after 7 days of bioremediation. (a) SW_CO: Sea water with crude oil. (b) SW_CO_NP: Sea water, crude oil and N and P nutrients. (c) SW_CO_NP_BS: Sea water, crude oil, $\mathrm{N}$ and $\mathrm{P}$ nutrients and BS-in-d $\mathrm{H}_{2} \mathrm{O} 0.4 \%$ w/v. 


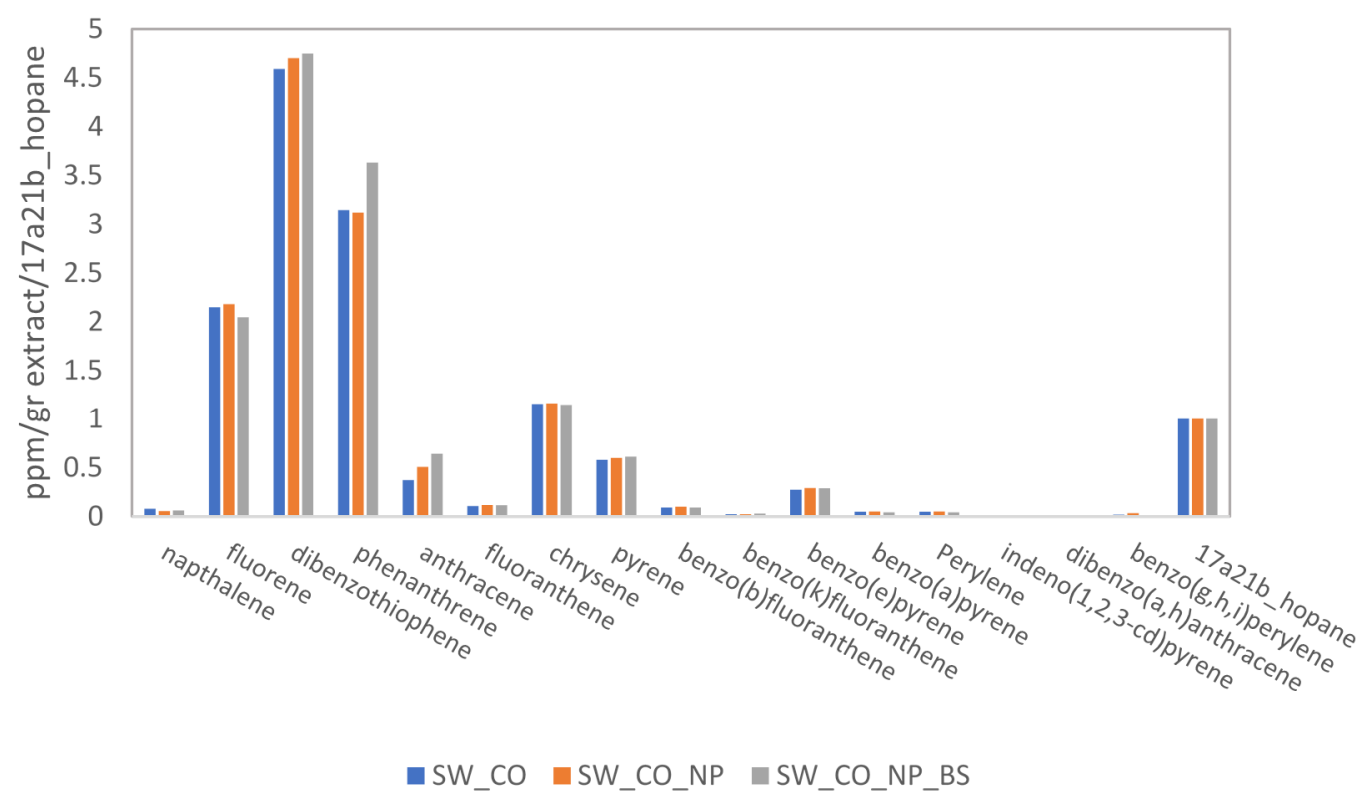

Figure A5. Bioremediation test results. Aromatic hydrocarbons concentration after 28 days of bioremediation. (a) SW_CO: Sea water with crude oil. (b) SW_CO_NP: Sea water, crude oil and $\mathrm{N}$ and P nutrients. (c) SW_CO_NP_BS: Sea water, crude oil, $\mathrm{N}$ and P nutrients and BS-in-dH $\mathrm{H}_{2} \mathrm{O}$ $0.4 \% w / v$.

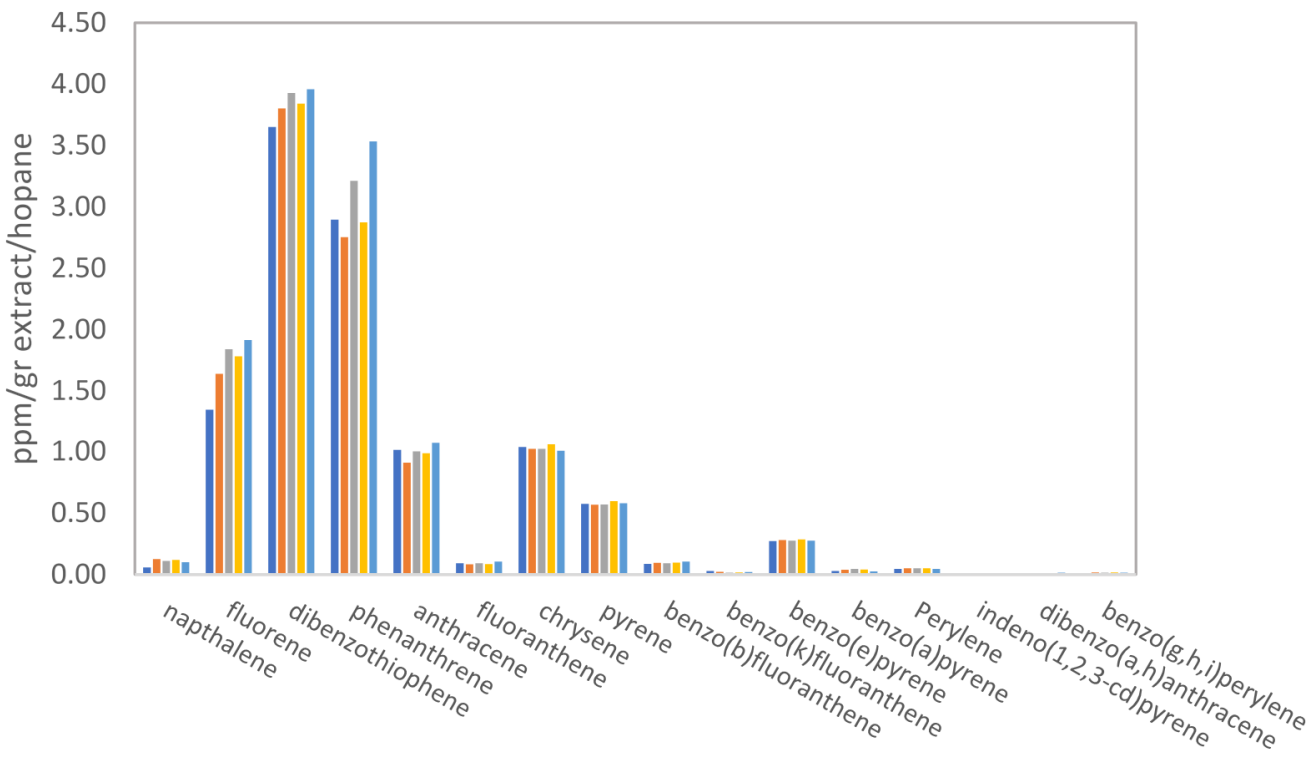

घW_CO $\square$ SW_CO_SOY $\square$ SW_CO_NP $\square$ SW_CO_NP_SOY $\square$ SW_CON_NP_15\%BS.IN.SOY

Figure A6. Bioremediation test results. Aromatic hydrocarbons concentration after 7 days of bioremediation. (a) SW_CO: Sea water with crude oil. (b) SW_CO_SOY: Sea water, crude oil and soybean oil. (c) SW_CO_NP: Sea water, crude oil and N and P nutrients (d) SW_CO_NP_SOY: Sea water, crude oil, N and P nutrients and soybean oil. (e) SW_CO_NP_15\%BS.IN.SOY: Sea water, crude oil, N and $P$ nutrients and BS-in-SOY agent $15 \% w / v$. 


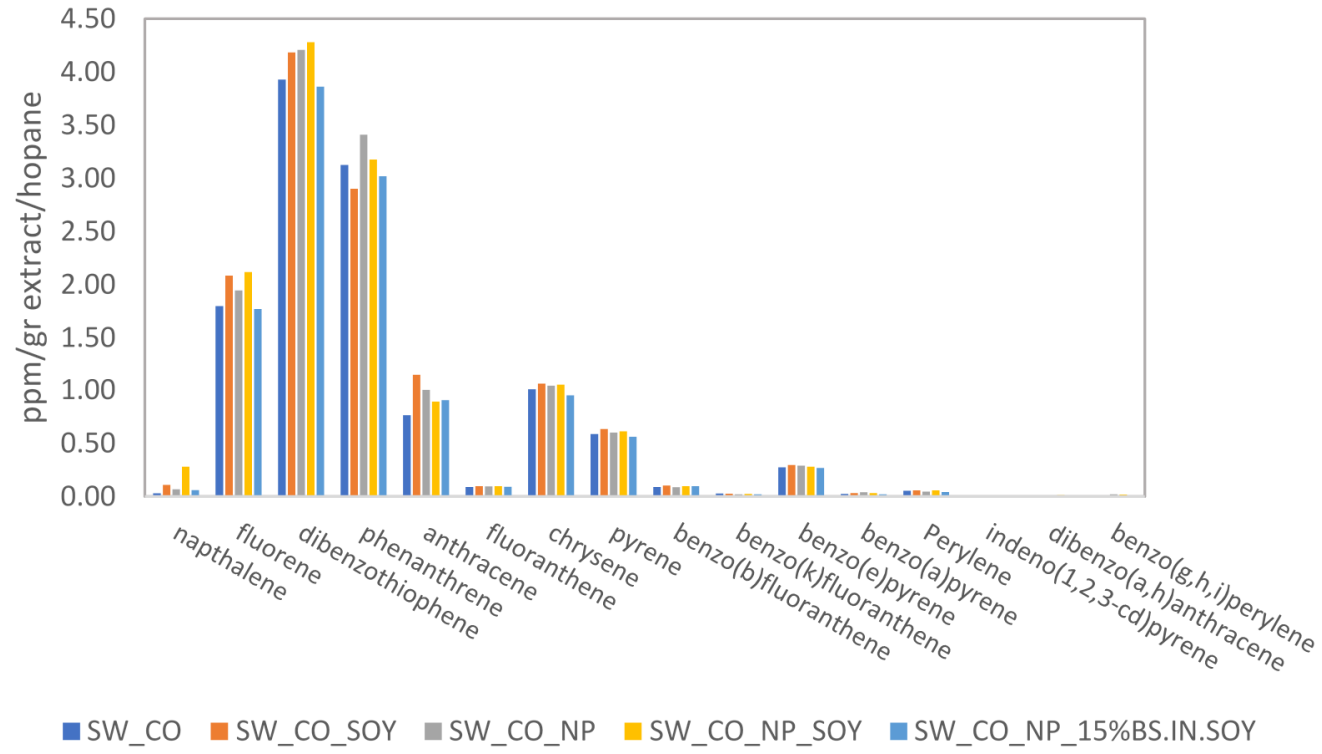

Figure A7. Bioremediation test results. Aromatic hydrocarbons concentration after 28 days of bioremediation. (a) SW_CO: Sea water with crude oil. (b) SW_CO_SOY: Sea water, crude oil and soybean oil. (c) SW_CO_NP: Sea water, crude oil and N and P nutrients. (d) SW_CO_NP_SOY: Sea water, crude oil, N and P nutrients and soybean oil. (e) SW_CO_NP_15\%BS.IN.SOY: Sea water, crude oil, $\mathrm{N}$ and P nutrients and BS-in-SOY agent $15 \% w / v$.

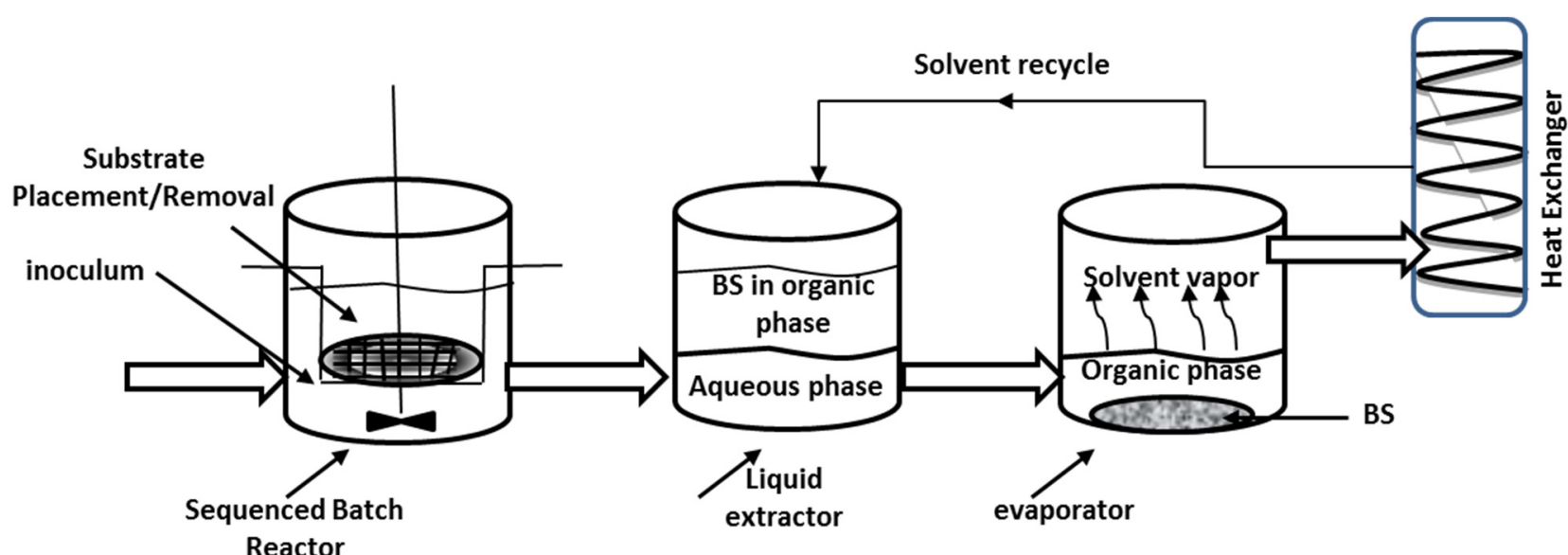

Figure A8. Production scheme of rhamnolipids using a sequencing batch reactor.

\section{References}

1. Nikolova, C.; Gutierrez, T. Biosurfactants and their applications in the oil and gas industry: Current state of knowledge and future perspectives. Front. Bioeng. Biotechnol. 2021, 9. [CrossRef]

2. Sambito, M.; Freni, G. Strategies for Improving Optimal Positioning of Quality Sensors in Urban Drainage Systems for NonConservative Contaminants. Water 2021, 13, 934. [CrossRef]

3. Sambito, M.; Severino, A.; Freni, G.; Neduzha, L. A Systematic Review of the Hydrological, Environmental and Durability Performance of Permeable Pavement Systems. Sustainability 2021, 13, 4509. [CrossRef]

4. Asejeje, G.I.; Ipeaiyeda, A.R.; Onianwa, P.C. Occurrence of BTEX from petroleum hydrocarbons in surface water, sediment, and biota from Ubeji Creek of Delta State, Nigeria. Environ. Sci. Pollut. Res. 2021, 28, 15361-15379. [CrossRef] [PubMed]

5. Santos, D.K.F.; Rufino, R.D.; Luna, J.M.; Santos, V.A.; Sarubbo, L.A. Biosurfactants: Multifunctional biomolecules of the 21st century. Int. J. Mol. Sci. 2016, 17, 401. [CrossRef]

6. Liu, G.; Zhong, H.; Yang, X.; Liu, Y.; Shao, B.; Liu, Z. Advances in applications of rhamnolipids biosurfactant in environmental remediation: A review. Biotechnol. Bioeng. 2018, 115, 796-814. [CrossRef] [PubMed]

7. Bertrand, B.; Martínez-Morales, F.; Rosas-Galván, N.S.; Morales-Guzmán, D.; Trejo-Hernández, M.R. Statistical design, a powerful tool for optimizing biosurfactant production: A review. Colloids Interfaces 2018, 2, 36. [CrossRef] 
8. Mazaheri Assadi, M.; Tabatabaee, M.S. Biosurfactants and their use in upgrading petroleum vacuum distillation residue: A review. Int. J. Environ. Res. 2010, 4, 549-572.

9. Patel, K.; Patel, M. Improving bioremediation process of petroleum wastewater using biosurfactants producing Stenotrophomonas sp. S1VKR-26 and assessment of phytotoxicity. Bioresour. Technol. 2020, 315, 123861. [CrossRef] [PubMed]

10. Pacwa-Płociniczak, M.; Płaza, G.A.; Piotrowska-Seget, Z.; Cameotra, S.S. Environmental applications of biosurfactants: Recent advances. Int. J. Mol. Sci. 2011, 12, 633-654. [CrossRef]

11. Sharma, D.; Ansari, M.J.; Al-Ghamdi, A.; Adgaba, N.; Khan, K.A.; Pruthi, V.; Al-Waili, N. Biosurfactant production by Pseudomonas aeruginosa DSVP20 isolated from petroleum hydrocarbon-contaminated soil and its physicochemical characterization. Environ. Sci. Pollut. Res. 2015, 22, 17636-17643. [CrossRef]

12. Freitas, B.G.; Brito, J.M.; Brasileiro, P.P.; Rufino, R.D.; Luna, J.M.; Santos, V.A.; Sarubbo, L.A. Formulation of a commercial biosurfactant for application as a dispersant of petroleum and by-products spilled in oceans. Front. Microbiol. 2016, 7, 1646. [CrossRef]

13. Cameotra, S.S.; Makkar, R.S.; Kaur, J.; Mehta, S.K. Synthesis of biosurfactants and their advantages to microorganisms and mankind. Biosurfactants 2010, 672, 261-280.

14. Jahan, R.; Bodratti, A.M.; Tsianou, M.; Alexandridis, P. Biosurfactants, natural alternatives to synthetic surfactants: Physicochemical properties and applications. Adv. Colloid Interface Sci. 2020, 275, 102061. [CrossRef] [PubMed]

15. Saharan, B.S.; Sahu, R.K.; Sharma, D. A review on biosurfactants: Fermentation, current developments and perspectives. Genet. Eng. Biotechnol. J. 2011, 2011, 1-14.

16. Xu, M.; Fu, X.; Gao, Y.; Duan, L.; Xu, C.; Sun, W.; Li, Y.; Meng, X.; Xiao, X. Characterization of a biosurfactant-producing bacteria isolated from Marine environment: Surface activity, chemical characterization and biodegradation. J. Environ. Chem. Eng. 2020, 8, 104277. [CrossRef]

17. Karlapudi, A.P.; Venkateswarulu, T.C.; Tammineedi, J.; Kanumuri, L.; Ravuru, B.K.; ramu Dirisala, V.; Kodali, V.P. Role of biosurfactants in bioremediation of oil pollution-A review. Petroleum 2018, 4, 241-249. [CrossRef]

18. Kaczorek, E.; Pacholak, A.; Zdarta, A.; Smułek, W. The impact of biosurfactants on microbial cell properties leading to hydrocarbon bioavailability increase. Colloids Interfaces 2018, 2, 35. [CrossRef]

19. Antoniou, E.; Fodelianakis, S.; Korkakaki, E.; Kalogerakis, N. Biosurfactant production from marine hydrocarbon-degrading consortia and pure bacterial strains using crude oil as carbon source. Front. Microbiol. 2015, 6, 274. [CrossRef]

20. Matvyeyeva, O.L.; Aliieva, O.R. Microbial biosurfactants role in oil products biodegradation. Int. J. Environ. Bioremediat. Biodegrad. 2014, 2, 69-74.

21. Rahman, P.K.; Gakpe, E. Production, characterisation and applications of biosurfactants—Review. Biotechnology 2008, 7, 360-370. [CrossRef]

22. Banat, I.M.; Franzetti, A.; Gandolfi, I.; Bestetti, G.; Martinotti, M.G.; Fracchia, L.; Smyth, T.J.; Marchant, R. Microbial biosurfactants production, applications and future potential. Appl. Microbiol. Biotechnol. 2010, 87, 427-444. [CrossRef] [PubMed]

23. Smyth, T.; Perfumo, A.; Marchant, R.; Banat, I. Isolation and Analysis of Low Molecular Weight Microbial Glycolipids. In Handbook of Hydrocarbon and Lipid Microbiology, 1st ed.; Timmis, K.N., Ed.; Springer: Berlin/Heidleberg, Germany, 2010; pp. $3705-3723$.

24. Sorial, G.A. Laboratory Testing to Determine Dispersion Predictability of the Baffled Flask Test (BFT) and Swirling Flask Test (SFT); Bureau of Safety and Environmental Enforcement (BSEE), US Department of the Interior: Washington, DC, USA, 2006. 